
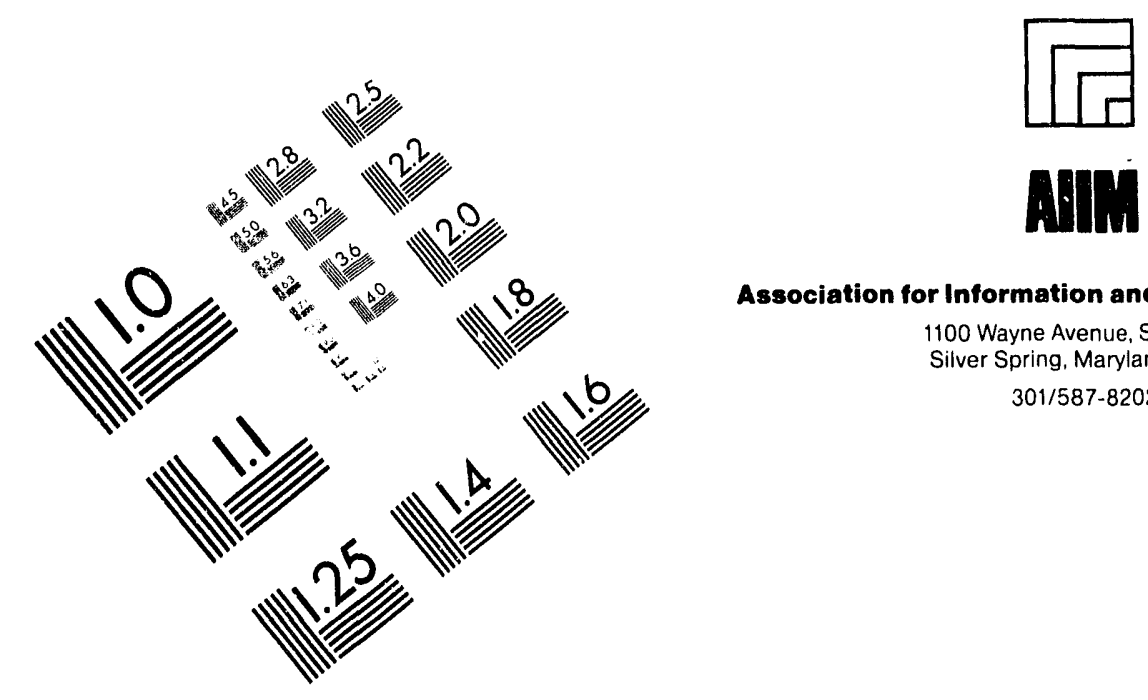

Association for Information and Image Management

1100 Wayne Avenue, Suite 1100

Silver Spring, Maryland 20910

$$
\text { 301/587-8202 }
$$

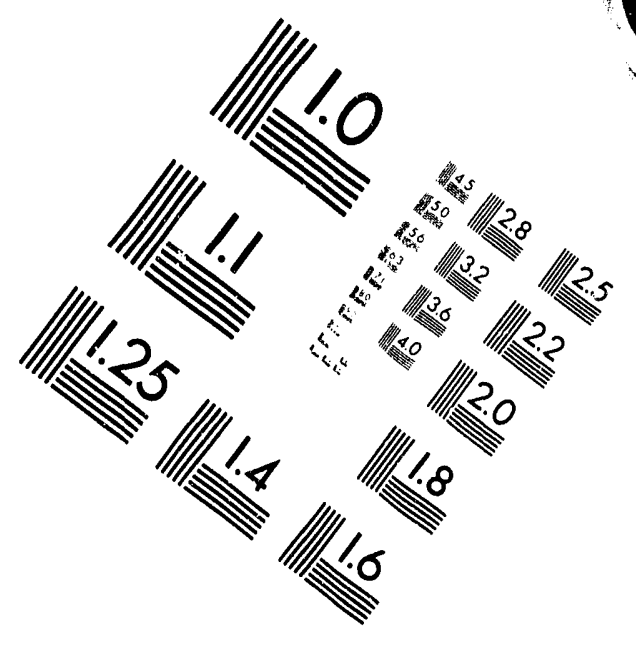

\title{
Centimeter
}

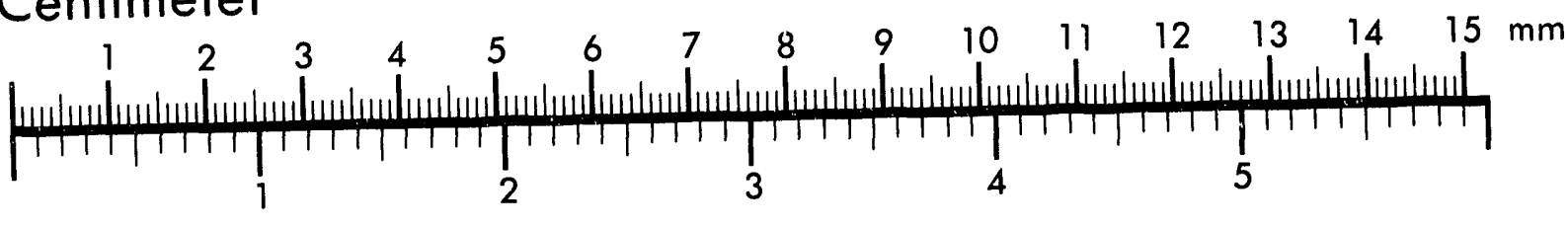
Inches
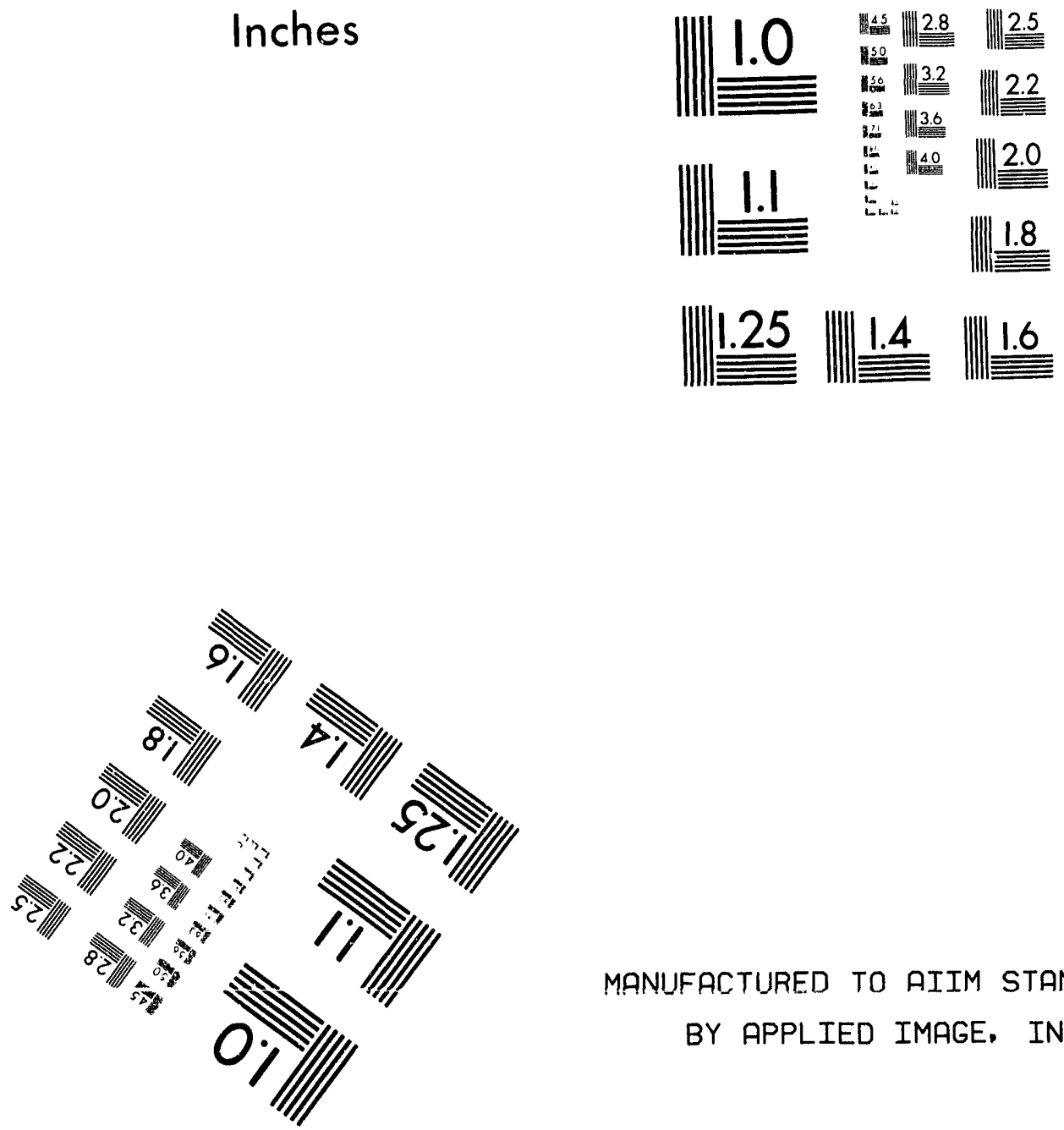

MANUFACTURED TO AIIM STANDARDS

BY APPLIED IMAGE. INC.

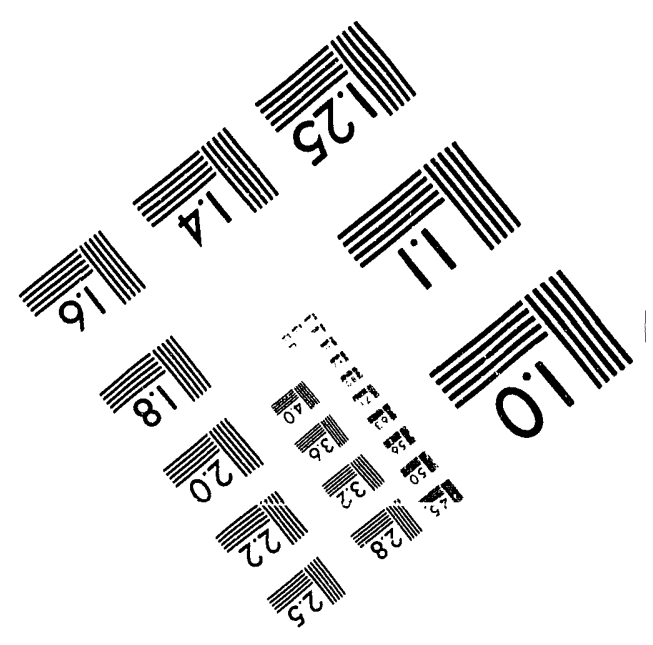



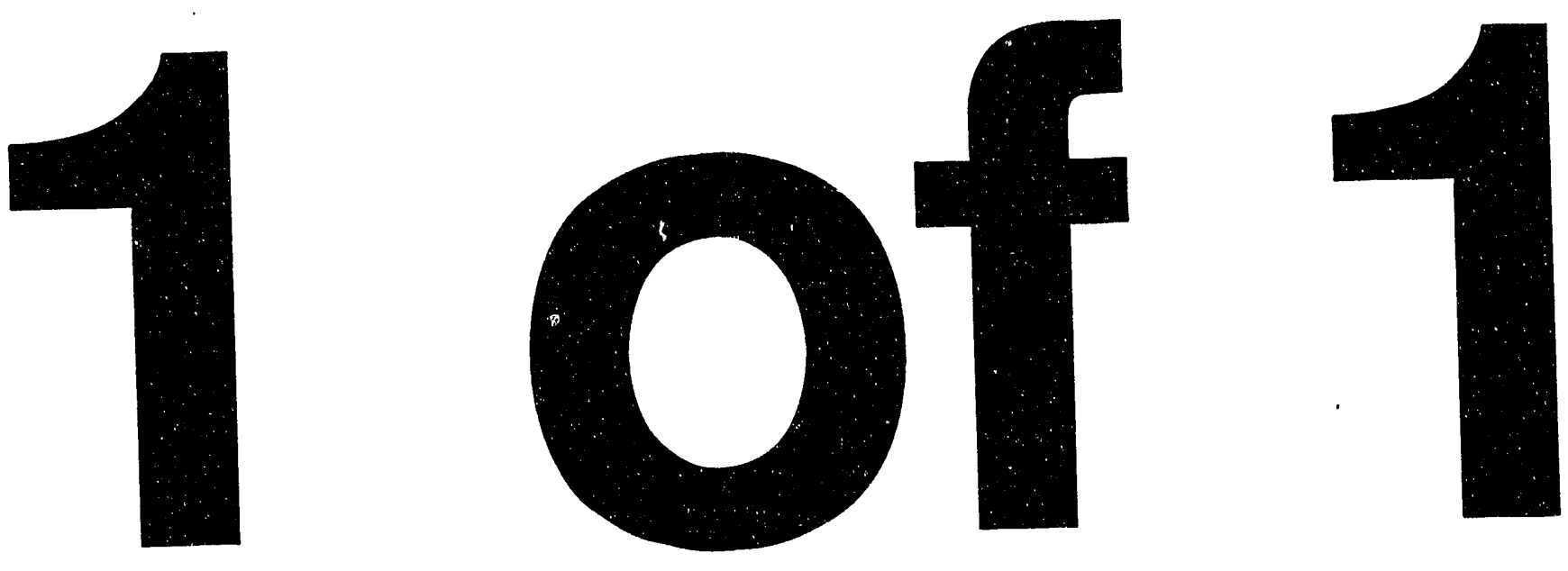


\section{RESEARCH PROGRESS REPORT}

In the previous progress report (March, 1992), three main objectives were listed for the intervening year: 1) Survey of ion channels in Arabidopsis; 2) Chemical characterization of the tonoplast cation channel (YVC1) in Saccharomyces; and 3) Characterization of a fungal proton pump cloned into mammalian cells. Progress on all three of these experimental lines, plus several new ones, is summarized below. In addition, continued work with the yeast plasmamembrane $\mathrm{K}^{+}$channel (YPK1) led to clear demonstrations that 4) gating of YPK1 depends upon the disequilibrium voltage for $\mathrm{K}^{+}$, rather than upon the absolute membrane voltage, and that 5) all channels observable in the yeast plasmalemma are unchanged in primary pump mutants. 6) Preliminary patch-clamp studies on the plasmalemma of Neurospora also identified two conspicuous cation channels in that membrane. And finally, a concerted effort to measure cytoplacmic pH in Saccharomyces and Neurospora by means of fluorescent pH indicators evinced two important findings: that 7) dyes taken up in (lipophilic) heavily esterified forms-e.g., the (multi)acetoxymethyl esters of BCECF and SNARFcalcein--accumulate in vacuoles, not in the cytosol; and that 8) the size and distribution of fungal vacuoles can be manipulated dramatically by altering carbon metabolism. In addition, several manuscripts previously listed as submitted or in press have been published: \#'s 1,2,3,4 below; and two tisted as in preparation have been submitted: \#'s 6,7 below.

Continuing Work on Channels in Arabidopsis Plasmalemma. Work was initiated previously in this laboratory by Dr. Adam Bertl and by Dr. Edgar Spalding (laboratory of M.H.M. Goldsmith, Yale Department of Biology) which led to a clear description of three distinct ion channels in the plasma membrane of Arabidopsis leaf mesophyll cells: i) a light-activated, weakly (outward) rectifying, $\mathrm{K}^{+}$-specific channel of ca. $40 \mathrm{pS}$ amplitude under standard conditions (dubbed PKC1, or APK1); ii) an outward rectifying K+-specific channel (APK2) of ca. 65 pS; and iii) an outward rectifying non-specific cation channel (APC1) of ca. 110 pS (see Progress Report of March, 1992, \& Plant Physiol. 99:96-102, 1992). Over the past year, Dr. Spalding has continued this work and has been able to show that cytoplasmic ATP increases the open probability of all three types of channels and, specifically, appears to be a necessary link in the light-activation pathway for APK1. He has also identified two additional types of channels, a mechanosensitive channel and an anion-selective channel, and has published a short report of the new findings (Spalding \& Goldsmith, \#5 below).

Yeast Tonoplast Chemistry. In the application for competitive renewal of this research grant, it was proposed to purify yeast vacuolar membranes, then, by means of calmodulinaffinity chromatography, to separate proteins related to the channel $\mathbf{Y V C 1}$, reconstitute them in liposomes and/or bilayer lipid films, verify the identity of one or more proteins with the physiological characteristics of YVC1, and--time \& funds permitting--make antibodies to the protein, as the beginning of a process to clone the structural gene for the channel. Over the past year, Ms. Esther Bashi has made substantial progress on the first parts of this project. Purification of vacuolar membranes from Saccharomyces proved more difficult than the literature (e.g., Kakinuma et al., J. Biol. Chem. 256:10859-10863, 1981; Roberts et al., Meth. Enz. 194:644-661, 1991) had indicated, partly because of severe strain-dependence in separation efficiency. At present Ms. Bashi is working with broken vacuolar vesicles wh:ch are approximately $90 \%$ pure, as judged by activity of the bafilomycin-sensitive ATPase, compared with azide- (mitochon-

DISTRIBUTION OF THIS DOCUMENT IS UNLIMITED

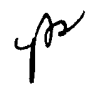


drial), and vanadate- (plasmalemmal) sensitive ATPases. This material is dissolved in $1.5 \%$ CHAPS, mixed with calmodulin-affinity beads in the presence of $\mathrm{Ca}^{++}$, then eluted with EGTA. Substantial vacuolar protein does in fact attached to the beads in a Ca+t-dependent fashion, and that protein is just now being spread on SDS gels.

Cloning of Fungal Pumps into Mammalian Cells. Dr. Liana Moussatos, formerly salaried by N.I.G.M.S. (individual NRSA) and now by the Donaghue Foundation, has completed a large block of experiments on cloning the Neurospora plasma-membrane $\mathrm{H}^{+-A T P a s e}$ gene (PMA1) into NIH-3T3 cells. Technical details of the cloning experiments have been noted in previous progress reports (March 1991 \& 1992), and the new results over the past year have concerned mainly localization of the heterologous protein and functional (physiological) characterization of the transformed strains. Protein expression. All 8 stable transfectant lines display two protein bands on SDS -PAGE, reactive with polyclonal anti-PMA1 antibody: one of $M_{r}$ $=100,000$ and one of $M_{r}=120,000$, the latter being preferentially expressed under normal growth conditions. Treatment of preconfluent cells with $15 \mathrm{mM}$ sodium butyrate, to stimulate transcription at the SV40 promoter to which the pma1 gene is linked, substantially increases expression of the 100-kD protein, and diminishes expression of the 120-kD protein. We believe the $120-\mathrm{kD}$ protein to be glycosylated at the one available $\mathrm{N}$-linked site (glutamine 714), and are now testing for blockade by tunicamycin.

Immunocytochemistry carried out with several antibodies to Neurospora pma1 enzyme revealed abnormal topology for the protein expressed in 3T3 cells. The 120-kD protein appears mostly at the plasma membrane (judged by immunoreactivity of intact cells), but substantially with the $\mathrm{N}$ - and $\mathrm{C}$-terminals located extracellularly, instead of intracellularly as in Neurospora itself (Mandala \& C.W. Slayman, J. Biol. Chem. 264:16276-16281, 1989). The 100-kD protein appears predominantly in intracellular membranes, presumably endosomes and ER, with large numbers of endosomes enlarged into vacuoles similar in size to those common in mycelial fungi (see below). A large fraction of cells in all transfected lines are also enlarged, sometimes into $100-\mu \mathrm{m}$ "fried eggs" containing hundreds of visible vacuoles. Such cells resemble osteoclasts.

Two kinds of tests have been carried out for $\mathrm{H}^{+}$-transporting activity of proton pumps in the transfected 3T3-cell lines. In one, cover-slip cultures are stained with putative cytoplasmic pH indicators, such as bis-(carboxyethyl)-carboxyfluorescein (BCECF-AM), and are then challenged by a cycle of acid-loading and relaxation under conditions of full blockade of proton exchangers native to 3T3 cells. Two of the stable transfectant lines show a clear vanadate-sensitive recovery of $\mathrm{pH}$, although only after the acid load has been sustained for 5-10 minutes. These same lines also demonstrate pump activity in (delayed) response to acid loading, when tested by patch-clamping; i.e., they produce an extra 100-200 pA of (hyperpolarizing) membrane current when subjected to acid loading. Such experiments provide a quantitative basis for comparison of expressed pumps with native pumps, work which will be continued over the coming year by $\mathrm{Dr}$. Moussatos. Two manuscripts on these results are now in preparation (items \#10 \& 11, below).

Voltage Modulation of Gating of YPK1. Gating control of the yeast plasma-membrane $\mathrm{K}^{+}$channel is complex, and under normal circumstances both unexpectedly high cytoplasmic $\left[\mathrm{Ca}^{++}\right]$and unexpectedly positive membrane voltages are required to open the channel (it is a strong outward rectifier). While several functional roles for such a channel can be postulated in 
Saccharomyces, a curious inconstancy in the half-gate voltage had been observed in earlier experiments (see discussion in Bertl et al., J. Exp. Biol. 172:271-287, 1992, Ref. \#xx below). In the past few months Dr. Bertl has examined this phenomenon systematically, and has shown that the controlling term is not membrane voltage $\left(V_{m}\right)$, per se, but the difference between the actual membrane voltage and the equilibrium voltage $\left(E_{K}\right)$ for potassium diffusion: $E_{K}-V_{m}$, which has been called the "disequilibrium potential" for potassium. The finding with yeast channels is clear-cut, and supports a fairly conjectural argument now raging about certain $\left(\mathrm{K}^{+}\right)$channels in nerve and muscle membrane.

Bogus Channel Activity in Yeast PM-ATPase Mutants. Aimong the hundreds of mutants of the yeast plasma-membrane $\mathrm{H}^{+}$-ATPase which have been obtained either by site-directed mutagenesis or by selection of random mutants, one which drew particular attention a few years ago was pma1-105, isolated under hygromycin-B selection and shown to have low resting membrane potentials and a partially uncoupled ATPase (Perlin et al., J. Biol. Chem. 263: $18118-18122,1988, \& 264: 21857-21864,1989)$. Rudimentary patch-clamp measurements were made on this strain (Ramirez et al., Proc. Natl. Acad. Sci. USA 86:7866-7870, 1989) from which $\mathrm{K}+$ channels displaying both outward and inward rectification (cosh-shaped I-V curve) were reported. These were said to be activated at small ( + or - ) membrane voltages by elevation of cytoplasmic ATP. After an exhaustive study of pma1-105 cells, kindly provided by Dr. J.E. Haber (Brandeis University) and detailed comparison with wild-type cells, Dr. Bertl has shown all clearly identified $\mathrm{K}^{+}$channels in both strains to have the same (strictly outwardrectifying) activity, without appreciable sensitivity to cytoplasmic ATP. Furthermore, Dr. Bertl has been able to reproduce this data of Ramirez et al. by recording not from isolated yeast membrane patches, but from small vesicles. These results and those on control of gating by the $\mathrm{K}^{+}$-disequilibrium potential are described in two manuscripts now being written (\#'s 12 \& 13 , below).

Identification of Ion Channels in Neurospora Plasma Membrane. In preparation for patch-clamp studies on the 3T3-cell membranes bearing fungal proton pumps, Dr. Moussatos first sharpened her skills by probing the more easily manipulated cells of a mutant wall-less (protoplast) strain of Neurospora. To our delight, with Dr. Bertl's careful tutelage, Neurospora protoplasts proved to be easy material--much easier than yeast protoplasts--for patch-clamp experiments. In a very short time three clearly distinct types of channels were observed in these membranes: an anion-selective channel and both inward- and outward-iectifying $\mathrm{K}^{+}$ channels. We hope it will be possible to continue this work under separate support.

Endosomal Accumulation of Lipid-soluble Dyes. It has become common practice in recent years to monitor intracellular $\mathrm{pH}$ in mammalian cells optically, by means of fluorescent $\mathrm{pH}$ indicator dyes. Preliminary efforts to use this same technique on Neurospora yielded a major surprise: dyes such as BCECF, after a few minutes of exposure, assume a strongly punctate distribution in all morphological torms of the organism: protoplasts, germinated conidia, and sometimes in mature mycelium. Such distribution is rarely reported in animal cells, and is coincident with a peculiar morphological feature of fungi: viz., that under many conditions endosomes aggregate to form vacuoles which are easily distinguishable by ordinary light microscopy. [In this feature fungi are a happy intermediate between animal cells and plant 
cells, since the former's endosomes normally remain submicroscopic, whereas the latter's swell large enough to obscure most other cytoplasmic structures.]

Since resolution of small organelles by light microscopy is very suboptimal even with highquality microscopes of ordinary design, Dr. Slayman investigated the problem using confocal microscopy, on sabbatical time at Cornell University (in the National Biotechnology Resource for electrooptics, directed by Prof. W.W. Webt). Several different kinds of dyes were tested, and the following conclusions were reached: a) Indeed, by confocal miscroscopy, dyes such as BCECF and SNARF-calcein, when loaded in as non-ionic esters (acetoxymethyl esters, -AM), quickly transit the cell wall and cytosol and accumulate in the vacuoles. b) Because the vacuoles are acidic, accumulation is not due to $\mathrm{pH}$-trapping. c) Rather, it most likely represents ionic trapping which results from hydrolysis by esterases localized in the vacuoles. d) Less lipophilic dyes, such as SNARF-AM, do not accumulate in the vacuoles and are not retained in the cytosol upon removal of extracellular dye. e) In such circumstances, average measurements of fluorescence via ordinary light microscopy cannot give valid estimates of cytosolic $\mathrm{pH}$, both because most of the dye is localized in organelles and because out-of-focus image noise can easily contaminate "clear area" signals. That imeans confocal optics are required. Finally, f) for typical cells with submicroscopic endosomes, the possibility is very high that loading of fluorescent dyes in esterified form simply deposits the fluorescence signal into unresolvable grains, still not in the cytosol itself. [This is a problem that animal physiologists should be deeply concerned about. They are not. Getting them concerned has been an uphill battle. See reference \#14, below. ]

Spinoffs: Control of Vacuolation in Fungi. Under normal laboratory conditions, most mycelial fungi contain one or two large-ish vacuoles per "cell", while evidently the bulk of endosomes remain of small size. Also under normal conditions many yeasts, particularly Saccharomyces cerevisiae, contain a single central vacuole occupying $20-25 \%$ of cytoplasmic volume, but also probably retain a major fraction of small endosomes. Various mechanical manipulations and metabolic changes appear to bias toward or away from consolidation of endosomes into visible vacuoles, but the relevant literature is rather random and inconclusive. Because deliberate growth of large vacuoles seemed a good way to systematize the observations on distribution of fluorescent $\mathrm{pH}$ indicators, Ms. Bashi undertook a survey of growth conditions which might systematically produce large vacuoles in Neurospora. She discovered one surefire condition: rapidly growing mycelium, when transferred to glucose free medium, stuffs itself with 3- to 5- $\mu \mathrm{m}$ (diameter) vacuoles over about a 3-hour period. The process requires oxygen, is not inhibited by alternative sugars (galactose, fructose), and reverses with a roughly symmetric time-course after glucose is readmitted. Vacuolar proliferation coincides with other responses to glucose starvation, such as increasing membrane resistance, increasingly effective scavanging of glucose by a derepressible transferase, and increasing "cyoplasmic" buffer capacity. The latter event, in fact, can probably be taken as a measure of the increase in total vacuolar volume, and is the subject of a manuscript, now being completed, on the (lack of) effect of $\mathrm{H}^{+}$-coupled glucose uptake upon cytoplasmic $\mathrm{pH}$ (item \#15, below).

\section{DISCLAIMER}

This report was prepared as an account of work sponsored by an agency of the United States Neither the United States Government nor any agency thereof, nor any of their employees, makes any warranty, express or implied, or assumes any legal liability or responsibility for the accuracy, completeness, or usefulness of any information, apparatus, product, or process disclosed, or represents that its use would not infringe privately owned rights. Reference herein to any specific commercial product, process, or service by trade name, trademark, manutacturer, or otherwise dues nut necessarily constitute or imply its endorsement, recommendation, or favoring by the United States Government or any agency thereof. The views and opinions of authors expressed herein do not necessarily state or reflect those of the

. P 
(Reprints of items $1,2,3, \& 5$ are enclosed).

\section{PUBLICATIONS}

\section{Now Published; Previously Reported as In Press or Submitted.}

1) Bertl, A., \& _ 1992. Complex modulation of cation channels in the tonoplast and plasma membrane of Saccharomyces cerevisiae: Single-channel studies. J. Exp. Biol. 172:271-287.

2) Bertl, A. \& Gradmann, D., 1992. Gating and conductance in an outward-rectifying $\mathrm{K}^{+}$ channel from the plasma membrane of Saccharomyces cerevisiae. J. Membr. Biol. 132:183-199.

3) 1992. Molecular correlates of physiological regulation in a P-type $\mathrm{H}^{+}$-ATPase, In Wallmark, B., J. Kaplan, S. Karlish, \& G. Sachs, eds., "Ion Pumps: Structure and Mechanism", Acta Physiol. Scand. 146:137-140, 1992.

4) 1993. Channels, pumps, and osmotic machines in plants: A tribute to Osterhout, In Barlow, R., J. Dowling, G. Weissman, \& P. Clapp, eds., The Biological Century: Friday Evening Talks at the Marine Biological Laboratory. Harvard University Press (Cambridge, MA). pp. 116-149.

\section{New Publication.}

5) Spalding, E.P., \& Goldsmith, M.H.M., 1993. Activation of $\mathrm{K}^{+}$channels in the plasma membrane of Arabidopsis by ATP produced photosynthetically. Plant Cell 5:477-484.

\section{Manuscripts Submitted.}

6) Ballarin-Denti, A., \& Kuroda, H., 1993. Lipid-soluble cations do not measure membrane voltage at the plasmalemmas of Neurospora or Saccharomyces. To Biochim. Biophys. Acta.

7) Kuroda, H., \& Ballarin-Denti, A., 1993. Lipid-soluble ions are taken up substantially in neutral form by Neurospora crassa. To Biochim. Biophys. Acta.

\section{Selected Abstracts.}

8) Moussatos, V., \& . Those proton pumps may be toxic! Expression of the Neurospora plasma membrane ATPase in cultured mammalian cells. Ninth Internat. Wkshp. Plant Membr. Biol.; Monterey, CA, July, 1992.

9) \& Moussatos, V.V. Endosomal sequestration of fluorescent indicator dyes: Vacuolar localization of BCECF in fungal cells and cultured mammalian fibroblasts. Abstr. XXXIInd Intern. Cong. Physiol. Sci., Glasgow, Aug., 1993. 


\section{Manuscripts in Preparation.}

10) Moussatos, V.V., Nakamoto, R.K., Slayman, C.W., Claudio, T., \& Heterologous expression of the Neurospora plasma membrane H-ATPase in murine fibroblasts: Regulation of posttranslational modifications, subcellular localization, and morphology, in NIH-3T3 cells.

11) Moussatos, V.V., \& A. Bertl. Physiological activation of a heterologous P-type ATPase in cultured fibroblast membranes: Patch-clamp recording of protor. currents due to a fungal ATPase expressed in NIH-3T3 cells.

12) Bertl, A., \& Control of $\mathrm{K}^{+}$-channel gating in the yeast plasma membrane by the transmembrane difference of electrochemical potential for potassium.

13) Bertl, A., and Haber, J.E. Normal activation of $\mathrm{K}^{+}$channels in yeast membranes bearing mutant PM-ATPase: Outward rectification and nucleotide-insensitivity of gating.

14) W.W. Webb, \& V.V. Moussatos. Vacuolar sequestration of fluorescent indicator dyes: Acetoxymethylester dyes are Trojan horses in fungal cells and in cultured mammalian fibroblasts.

15) D. Sanders, U.-P. Hansen, K.E. Allen, and V.V. Moussatos. Tricks of cytoplasmic buffering: Why massive proton-coupled sugar uptake does not alter cytoplasmic $\mathrm{pH}$ in Neurospora. 

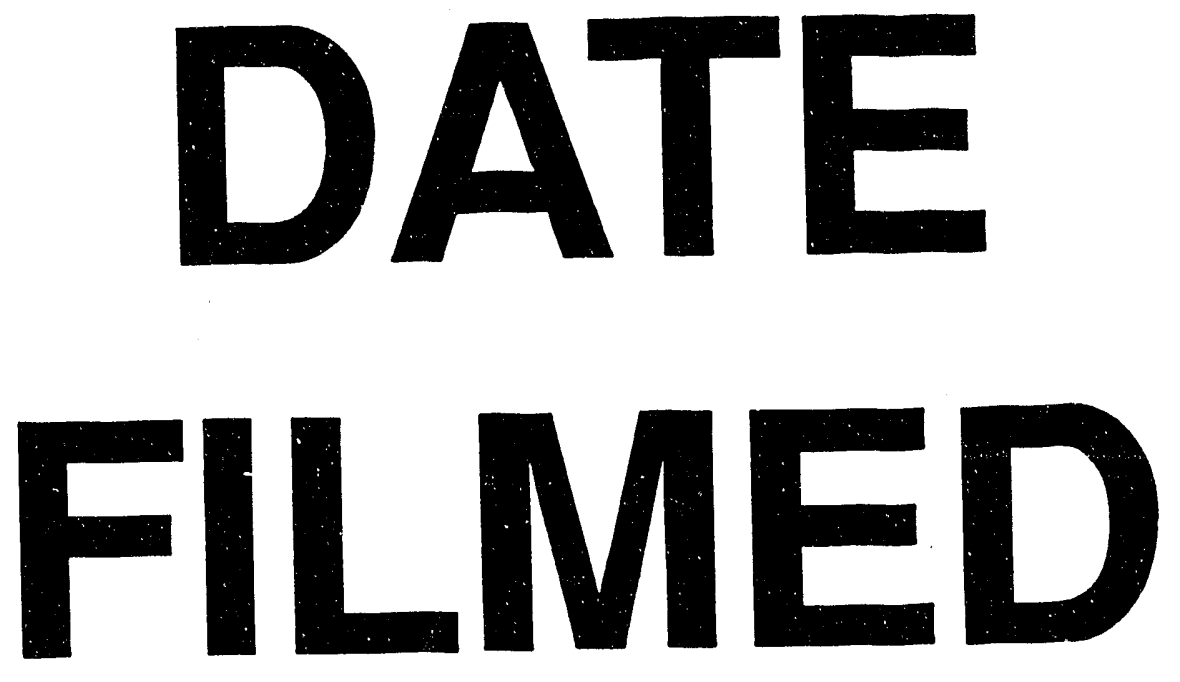

$8 / 13 / 93$
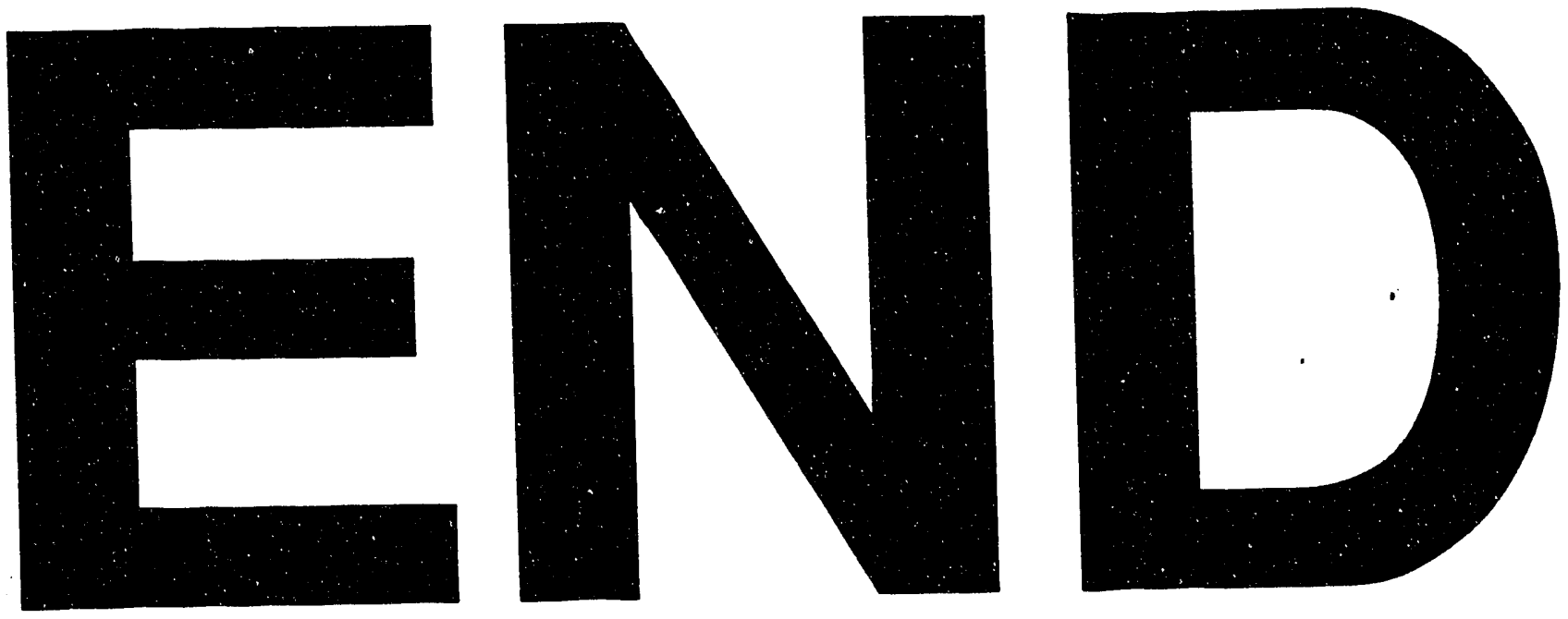
